\title{
Production of Functional Hepatobiliary Organoids from Human Pluripotent Stem Cells
}

\author{
Di Wu ${ }^{1}$, Xiaoni Chen ${ }^{1}$, Qingshou Sheng ${ }^{2}$, Wenlin Chen $^{2}$, Yuncheng Zhang ${ }^{2}$, Fenfang Wu ${ }^{1}$ \\ ${ }^{1}$ Department of Central Laboratory, Shenzhen Hospital, Beijing University of Chinese Medicine, Shenzhen, China \\ ${ }^{2}$ Department of Hepatology, Shenzhen Hospital, Beijing University of Chinese Medicine, Shenzhen, China
}

The research on human hepatobiliary development and disorders has been constrained by minimal access to human fetal tissue, and low accuracy of animal models. To overcome this problem, we have established a system for the differentiation of human pluripotent stem cells (hPSCs) into functional hepatobiliary organoids (HBOs). We have previously reported that our 45-d approach closely mimics key stages of hepatobiliary development, starting with the differentiation of hiPSC into endoderm and a small part of mesoderm, and subsequently into hepatoblast-like cells, followed by the parallel generation of hepatocyte-like cells and cholangiocyte-like cells, formation of immature HBO expressing early hepatic and biliary markers, and mature HBO displaying hepatobiliary functionality. In this study, we present an updated version of our previous protocol, which only needs 35 days to achieve maturation in vitro. Furthermore, a hepatobiliary culture medium is developed to functionally maintain the HBOs for more than 1.5 months. The capacity of this approach for producing large amounts of functional HBOs and enabling long-term culture in vitro holds promise for applications on developmental research, disease modeling, as well as screening of therapeutic agents.

Keywords: Hepatobiliary, Organoids, Differentiation, Pluripotent stem cells

\section{Introduction}

Pluripotent stem cells (PSCs), displaying unlimited proliferation ability and the multi-lineage differentiation potential, have emerged as an alternative and reproducible source of primary cells with therapeutic interest (1). The improvement of PSCs-based liver modeling systems can be

Received: September 21, 2020, Revised: November 9, 2020,

Accepted: November 18, 2020, Published online: December 31, 2020 Correspondence to Fenfang Wu

Department of Central Laboratory, Shenzhen Hospital, Beijing University of Chinese Medicine, No.1, Dayun Road, Longgang District, Shenzhen 518100, China

Tel: +86-14776939431, Fax: +86-075589911130

E-mail: wufenfang19@126.com

(a) This is an open-access article distributed under the terms of the Creative Commons Attribution Non-Commercial License (http://creativecommons.org/ licenses/by-nc/4.0/), which permits unrestricted non-commercial use, distribution, and reproduction in any medium, provided the original work is properly cited.

Copyright (c) 2021 by the Korean Society for Stem Cell Research exemplified by the transition from monolayer hepatic-like cells (2-5) to the 3D liver micro-tissues with improved functionality $(6,7)$. However, models in these studies are lack of a number of critical cell types such as biliary epithelial cells. Cholangiocytes line the biliary tracts, and facilitate the transport, modification, and secretion of bile from the liver into the luminal gastrointestinal tract (8, 9 ). These functions have been proved essential to maintain cell viability and functionality of the hepatic counterpart both in vivo and in vitro $(10,11)$. To date, despite several methods could respectively differentiate human PSCs into functional hepatocyte-like cells (2-5) or cholangiocyte-like cells (12-14), none are able to generate a hepatic organoid containing biliary structures, which is now considered as a critical hurdle to overcome for allowing the organoids being more refined and mature (15).

To address this issue, we have recently established a hPSC-derived hepatobiliary organoids (HBO) system (16). Herein, we present an updated version of our previous described 45-day protocol in detail, whereby a timing of 
35-day protocol to obtain the mature HBO. Furthermore, a hepatobiliary culture medium is developed to functionally maintain the organoids for more than 1.5 months, therefore enabling the in vitro applications that require a long-term manipulation, such as repeated dosing and disease modelling.

\section{Materials and Methods}

\section{Pluripotent stem cells}

The human embryonic stem cells we used are $\mathrm{Hl}$ and H9 cells (WA01 and WA09, Wicell Research Institute, cat. no. WB16217 and RB40917). The human iPSC lines are UC and WD cells (UC-S0730C11 and WD1-KSR-3, Chunshui Bioscience \& Technology, 0109 and 0105).

\section{Differentiation of hPSCs into endoderm and mesoderm}

PSCs were plated onto pre-coated $3 \mu \mathrm{g} / \mathrm{ml}$ laminin 521-111 (mixed with a ratio of $1: 3$, BioLamina, LN52102 and LN111-02). At the day before differentiation, cells were seeded at the density of $2.5 \times 10^{5}$ cells viable cells $/ \mathrm{cm}^{2}$, which would reach $90 \%$ confluency after attachment for the initiation of differentiation. Pre-stimulation was conducted at $90 \sim 95 \%$ confluency by replacing mTeSR1 (STEMCELL Technologies, 85850) with Pre-endoderm and -mesoderm Medium (Pre-EMM) for 5 hours: RPMI 1640 containing 2\% B27 supplement (minus insulin) (Life Technologies, A1895601), $100 \mathrm{ng} / \mathrm{ml}$ Activin A (PeproTech, 120-14P), and $20 \mathrm{ng} / \mathrm{ml} \mathrm{BMP4} \mathrm{(PeproTech,} \mathrm{120-05ET).}$ The medium was then replaced with EMM-1 (5\% mTESR1, 2\% B27 supplement (minus insulin), $100 \mathrm{ng} / \mathrm{ml}$ Activin $\mathrm{A}$, and $20 \mathrm{ng} / \mathrm{ml} \mathrm{BMP} 4$ ) for 2 days and EMM-2 (5\% mTeSR1, 2\% B27 supplement (minus insulin), 100 $\mathrm{ng} / \mathrm{ml}$ Activin A) for another 2 days.

\section{Differentiation of endoderm into hepatoblast-like cells}

The cultures at day 5 were placed in Progenitor Medium (PM) for 5 days: RPMI1640 containing 5\% mTeSR1, 2\% B27 supplement (Gibco, 17504044), 30 ng/ml FGF4 (Peprotech, 100-31) and $20 \mathrm{ng} / \mathrm{ml} \mathrm{BMP2}$ (Peprotech, 120-02C). The medium was then replaced with Expansion Medium (EM) for additional 5 days: RPMI1640 containing 5\% mTeSR1, 2\% B27 supplement, $20 \mathrm{ng} / \mathrm{ml} \mathrm{KGF}$ (Peprotech, 100-19), 20 ng/ml HGF (Peprotech, 315-23), 1\% GlutaMAX (Gibco, 35050061) and 1\% NEAA (Gibco, 11140050). No transfer operation was needed.

\section{Hepatobiliary differentiation and maturation}

The cultures at day 16 were placed in Hepato-biliary Differentiation Medium (HBDM) for 10 days: HCM
(Lonza, CC-3199 \& CC-4182) containing 20 ng/ml OSM (Peprotech, 300-10), 5\% Cholesterol ${ }^{+}$-MIX (ProbeChem, PC-35742), 1\% GlutaMAX and 1\% NEAA. The medium was then replaced with Hepato-biliary Maturation Medium (HBMM) for additional 10 days: HCM containing 20 ng/ml OSM, 5\% Cholesterol ${ }^{+}$-MIX, $0.5 \mu$ M Dexamethasome (Sigma-Aldrich, D1756), $2 \mu \mathrm{M}$ Vitamin K2 (Selleck, S5082), $5 \mu \mathrm{M}$ Lithocholic acid (Selleck, S4003). No transfer operation was needed.

\section{In vitro Maintenance of $\mathrm{HBOs}$}

The HBOs were placed in Hepato-biliary Culture Medium (HBCM): William's E medium (Gibco, A1217601) containing 2.5\% Cholesterol $^{+}$-MIX, 1\% ITS +3 (SigmaAldrich, I2771), 10\% KSR (Gibco, 10828028), $20 \mathrm{ng} / \mathrm{ml}$ HGF, 20 ng/ml EGF (Peprotech, 100-47), 10 ng/ml VEGF (Peprotech, 100-20C), 10 ng/ml FGF2 (Peprotech, 10018B), 1\% GlutaMAX and 1\% NEAA, which can functionally maintain the HBOs for about 50 days. No transfer operation was needed.

\section{Immunofluorescence}

Monolayer staining: the cultures displayed monolayer form (differentiation day $0,4,9,15$ ) were fixed with $4 \%$ paraformaldehyde (PFA) for 20 mins at room temperature (RT), and permeabilized with $0.2 \%$ Triton X-100 (SigmaAldrich, T8787) or cold $100 \%$ methanol. After blocking with 10\% donkey serum (The Jackson Laboratory, 017000-121) for 1 hour, the cells were incubated with primary antibodies in $1 \%$ donkey serum at $4{ }^{\circ} \mathrm{C}$ overnight, and secondary antibodies in 1\% donkey serum for 45 mins at RT. Finally, DAPI (Sigma-Aldrich, D8417) was used to counterstain the nuclei. Samples were washed 4 times with PBS for $5 \mathrm{~min}$ at RT after primary and secondary antibody and DAPI staining.

The 3D structure staining was performed as follows: 3D samples (differentiation day 25, 35) were fixed with $4 \%$ PFA at RT overnight, washed with normal saline $(0.85 \%$ $\mathrm{NaCl}$ ) and then embedded in Richard-Allan Scientific HistoGel (Thermo Scientific, HGSK-2050-1). The HistoGel block was dehydrated, embedded in paraffin and sectioned at $4 \mu \mathrm{m}$. Paraffin-embedded sections were dewaxed with xylene, rehydrated, placed in Tris-EGTA-buffer ( $\mathrm{pH} 9.0$ ) or citrate buffer ( $\mathrm{pH}$ 6.0) and subjected to heat mediated antigen retrieval (Microwave) for 20 mins. The subsequent staining steps are described above (as per monolayer staining).

All immunofluorescence images were acquired using a Leica TCS-SP5 confocal microscope. LAS X software (Leica) was used for image processing. A complete list of 
the primary and secondary antibodies used is shown in Supplementary Table S1.

\section{Flow cytometry}

Samples were incubated with TrypLE (Gibco, 12604013) at $37^{\circ} \mathrm{C}$ until the cells began to dissociate. Cells were centrifuged and resuspended in $2 \% \mathrm{PFA}$ at $4{ }^{\circ} \mathrm{C}$ for 20 mins and centrifuged and resuspended in flow cytometry buffer (PBS containg 5\% FBS and $0.1 \%$ Triton X-100). Cells were then incubated with primary antibodies or control IgGs for 30 mins on ice, and secondary antibodies for 20 mins on ice. Analysis was performed using a FACS LSR Fortessa flow cytometer (BD Biosciences). IgG controls were used to set gates for positive cells.

\section{Albumin and urea assay}

Albumin and Urea production were detected using ELISA kit (Bethyl Laboratories, E88-129) and Quantichrom Urea assay Kit (Bioassay Systems, 360-DIUR-100), respectively. Cells were incubated in fresh medium for 24 hours and subsequently the cell supernatant was collected at different time points and analyzed for albumin secretion. Cells were either trypsinized and counted using a hemocytometer, or lysed for protein content assay with a BCA Protein Assay Kit (Thermo Scientific, 23225).

\section{CYP3A4 activity and inductivity}

CYP3A4 activity was measured using p450-Glo assay kit (Promega, V9001). Briefly, the organoids, cryopreserved human hepatocytes (Lonza, HUCPI) and HepG2 cells (ATCC, HB-8065) were rinsed in HCM and incubated with the luminescent substrate ( $3 \mathrm{mM}$ luciferin-IPA) and then cells were diluted in the same medium for 1 hour at $37^{\circ} \mathrm{C}$. Following incubation, supernatants were processed in accordance with the manufacturer's instructions. Luminescence was measured using a luminometer (GloMax Discover, Promega).

For CYP3A4 induction assays, cultures were treated with $25 \mu \mathrm{M}$ rifampin (Sigma-Aldrich, R3501) or $0.1 \%$ vol/vol DMSO control dissolved in HCM for 48 hours, followed by quantification of CYP3A4 activity using the luminescent assays described above. Inducer compounds were replaced daily.

\section{Alkaline phosphatase staining}

Alkaline phosphatase (ALP) staining was carried out using the BCIP/NBT color development substrate (5-bromo4-chloro-3-indolyl-phosphate/nitro blue tetrazolium) (Promega, S3771) according to the manufacturer's instructions.

\section{Measurement of $\gamma$-glutamyl transferase activity}

$\gamma$-glutamyl transferase activity (GGT) was measured in triplicate using the MaxDiscovery GGT Enzymatic Assay Kit (Bio Scientific, 5601-01) in accordance with the manufacturer's instructions. Substrate only was used as the negative control. Human intrahepatic biliary epithelial cells (ScienCell, 5100) was used as positive control.

\section{Results}

The HBO was produced from hPSC through a step-wise differentiation process that mimics hepatobiliary development. The differentiation stages with corresponding morphological features were shown in Fig. 1.

\section{Differentiation of hPSCs into bipotent hepatoblasts}

At the day before differentiation, the pluripotency of human PSC was examined by immunofluorescence and flow cytometry: pluripotent marker such as OCT4 and NAONG were co-stained by more than $98 \%$ cells (Fig. 2A).

As described previously, the signaling from mesodermal derivatives was important to achieve the co-differentiation of hepatic and biliary lineages (16). Therefore, the first target in this protocol is to simultaneously trigger endodermal and mesodermal fate. When the confluence of PSCs at day 0 reached $90 \sim 95 \%$, a 5-hour pre-stimulation was performed using pre-EMM, leading to detachment and death for a part of cells, as typical morphology of the culture shown in Fig. 1B (Day 0 5 h). After that, EMM-1 and EMM-2 were sequentially used for both 2 days, to promote differentiation of the two germ layers. By the end of day 4, More than 70\% cells co-expressed definitive endoderm marker SOX17 and FOXA2 (17), over 10\% cells expressed mesoderm marker BRA (18), whereas very few cells expressed ectoderm marker NESTIN (Fig. 2B) (19).

For next stage, PM was used for 5 days to promote the differentiation of hepatic progenitors. Immunofluorescence and flow cytometry analyses showed more than $60 \%$ of the cells co-expressed early hepatic marker HNF4A and AFP (20) by day 9. EM was then applied for additional 5 days to expand the progenitors, making the proportion of $\mathrm{AFP}^{+}$population increased to over $80 \%$. In the meantime, a minimum of $50 \%$ of cells co-expressed AFP and SOX9 (biliary marker) (Fig. 2D), which represents the feature of bipotent hepatoblasts (21). 

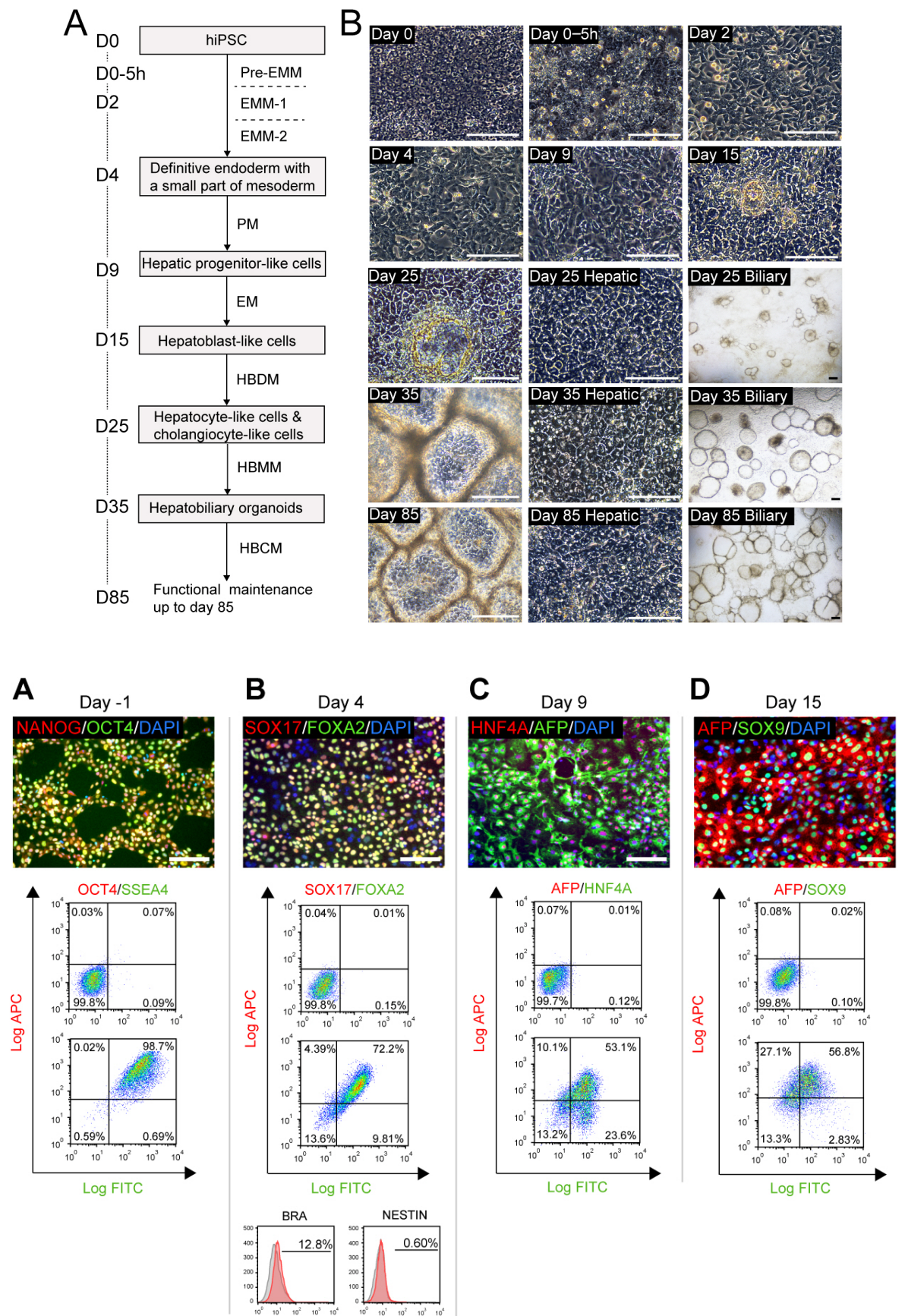

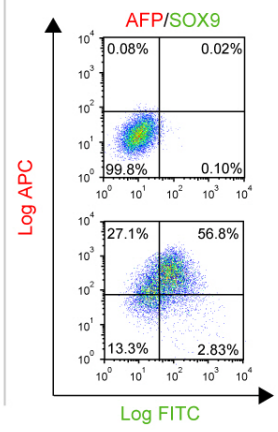

Fig. 1. Differentiation of hPSC into hepatobiliary organoids (HBOs). (A) Schematic presentation of the protocol for the generation of hPSC-derived HBOs. (B) Bright-field images of cells at key stages of $\mathrm{HBO}$ differentiation. The procedure steps and day numbers corresponding to each image are noted for reference. Scale bars, $150 \mu \mathrm{m}$. EM, expansion medium; EMM, endoderm and mesoderm medium; HBCM, hepato-biliary culture medium; HBDM, hepato-biliary differentiation medium; HBMM, hepato-biliary maturation medium; PM, progenitor medium.
Fig. 2. Molecular phenotype and differentiation efficiency at key stages of $\mathrm{HBO}$ differentiation. $(\mathrm{A} \sim \mathrm{F})$ At the end of each key stage, characteristic markers and differentiation efficiency were examined by immunofluorescence and flow cytometry, respectively. Scale bars, $100 \mu \mathrm{m}$. 


\section{Differentiation of bipotent hepatoblasts into HBOs}

At day 16, HBDM was used for 10 days to differentiate hepatoblast-like cells into early HBOs. During this stage, some $\mathrm{CK} 19^{+}$biliary structures began to appear, and the underlying $\mathrm{ALB}^{+}$hepatic lineage exhibits distinct nuclei/nucleoli and more cobblestone-like morphology, as identified in Fig. 1B (Day 25) and Fig. 2E. By day 25, over $70 \%$ of the cells expressed ALB, while over $15 \%$ of the cells expressed CK19 by flow cytometric analysis.

To promote the maturation of HBOs, HBMM was used for another 10 days. For morphology, a clearly more clustered appearance of hepatic cells and a higher number of biliary cysts could be observed during this stage (Fig. 1B (Day 35)). The proportions of the two lineages would be overall stable by flow cytometric analysis (Fig. 2F). In addition, mature hepatic marker CYP3A4 and biliary marker CK7/Ac- $\alpha$-tubulin/CFTR (22) can be identified at the end of this stage (Fig. 2F, Supplementary Fig. S1).

\section{In vitro culture of $\mathrm{HBO}$}

In this stage, $\mathrm{HBCM}$ was applied to culture the HBOs, which could functionally maintain the organoids for about 50 days in vitro. Functional examination can be performed during this period. As shown in Fig. 3A, the albumin secretion of day-35 HBOs was comparable to that in cryopreserved human adult hepatocytes $(7.21 \pm 1.20$ vs $12.92 \pm 2.60 \mu \mathrm{g} / \mathrm{ml} /$ day $/ \mathrm{mg}$ protein, $\mathrm{p}=0.09$ ) when normalized using protein content; whereas the urea production was lower than primary hepatocytes $(49.21 \pm 8.47$ vs $112.44 \pm 16.50 \mu \mathrm{g} / \mathrm{ml} /$ day $/ \mathrm{mg}$ protein, $\mathrm{p}<0.05)$. hPSCs showed no production of albumin and urea. The CYP3A4 activity of HBOs was not decreased from day 35 to day $80(0.21 \pm 0.06$ vs $0.19 \pm 0.04$ relative light unit $/ \mathrm{ml} / \mathrm{day} / \mathrm{mg}$ protein, $\mathrm{p}=0.79$ ) (Fig. 3B). In addition, when dosing with inducer such as rifampin, both day- 35 and day- $80 \mathrm{HBOs}$ demonstrated significant induction (over DMSO-treated control by 1.4-2.6-fold and 1.5-2.8-fold, $\mathrm{p}<0.05$ and $\mathrm{p}<$ 0.05 , respectively). Whereas primary hepatocytes were more robustly induced (2.2-3.4-fold, $\mathrm{p}<0.01)$. For biliary function, ALP activity was confirmed, as shown in Fig. 3C. Moreover, GGT activity of day- 35 and day- 80 HBOs was comparable to that in human intrahepatic biliary epithelial cells (Fig. 3D).

\section{Trouble shooting}

A Troubleshooting table was shown in Table 1.

\section{Discussion}

The research on the mechanisms of human hep-
A

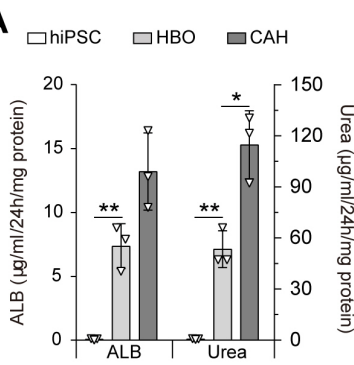

C

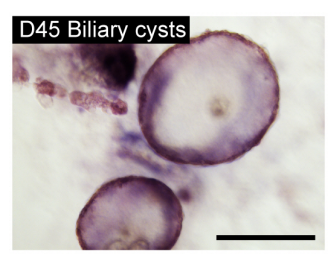

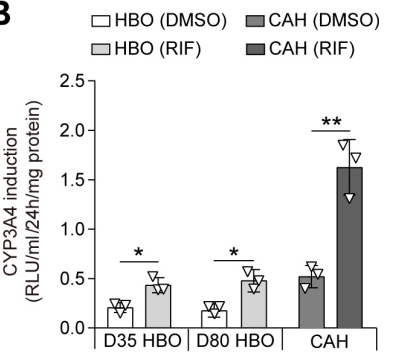

D

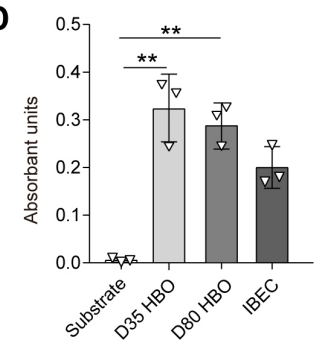

Fig. 3. Functional properties of hPSC-derived HBOs. (A) Production of albumin and urea in day-35 HBOs. Cryopreserved adult hepatocytes $(\mathrm{CAHs})$ were used as positive controls; hPSCs were used as negative control. ${ }^{*} p<0.05 ;{ }^{* *} p<0.01 ; n=3$. (B) CYP3A4 induction in day-35 and day-80 HBOs. The HBOs were treated with $25 \mu \mathrm{M}$ rifampin (RIF), followed by assessment of CYP3A4 activity using bioluminescent substrates. $\mathrm{CAH}$ were used as positive control. ${ }^{*} \mathrm{p}<0.05 ;{ }^{*} \mathrm{p}<0.01 ; \mathrm{n}=3$. (C) The biliary structures in HBOs demonstrating characteristic ALP staining. Scale bars, $100 \mu$ m. (D) GGT activity in day-35 and day-85 HBOs. Human intrahepatic biliary epithelial cells (IBEC) was used as positive control; substrate only was used as negative control. ${ }^{*} \mathrm{p}<0.01 ; \mathrm{n}=3$.

atobiliary development is limited by the poor access to human fetal tissue, and lower accuracy of animal models (23). Our hPSC-derived HBO system could address some of these challenges, as it relies on a stepwise differentiation procedure that closely mimics the embryonic hepatogenesis, including the generation of hPSC-derived hepatoblast-like cells, specification of this population to hepatocytic and biliary fate, and then the induction and formation of the complex organoids with hepatic clusters and biliary structures. In this regard, researchers can use our protocol to produce substantial numbers of cells corresponding to different embryonic stages of the liver, facilitating the mechanistic studies on hepatobiliary specification.

Mutations in hepatobiliary genes have been revealed in many liver diseases such as non-alcoholic fatty liver disease (24) and Alagille syndrome (25). However, rodent models often fail to recapitulate human pathophysiology $(26,27)$. Our approach can therefore be utilized in combination with genome editing technologies such as CRISPR/ Cas9 (28) to produce isogenic hPSC lines that differ only 
Table 1. Troubleshooting table

\begin{tabular}{|c|c|c|}
\hline Problem & Possible reason & Solution \\
\hline Poor attachment & Old Y27632 & Use fresh Y27632 and do not withdraw within $24 \mathrm{~h}$. \\
\hline \multirow[t]{2}{*}{$\begin{array}{l}\text { Cells do not recover or grow } \\
\text { slowly }\end{array}$} & $\begin{array}{l}\text { Unhealthy cells at } \\
\text { cryopreservation }\end{array}$ & Thaw a healthy one \\
\hline & $\begin{array}{l}\text { Insufficient habituation of } \\
\text { hPSCs on Laminin }\end{array}$ & $\begin{array}{l}\text { Gradually reduce the concentration of Laminin } 521 \text { at an interval of } 2 \\
\text { passages until reaching the target concentration of } 3 \mu \mathrm{g} / \mathrm{ml}\end{array}$ \\
\hline \multirow[t]{7}{*}{$\begin{array}{l}\text { Poor endoderm } / \text { mesoderm } \\
\text { commitment }\end{array}$} & Variability between lines & $\begin{array}{l}\text { Redefine the most efficient concentration of BMP4 }(10 \sim 20 \mathrm{ng} / \mathrm{ml}) \text { and } \\
\text { mTeSR } 1(5 \sim 10 \%) \text { in EMM1/2 }\end{array}$ \\
\hline & Poor quality of hPSC & Recheck the pluripotent markers and karyotype of hPSC \\
\hline & High passage cultures & Initiate the differentiation within 10 passages after cell thawing \\
\hline & $\begin{array}{l}\text { Inappropriate starting } \\
\text { confluence }\end{array}$ & Strictly control the plating density and starting confluence \\
\hline & $\begin{array}{l}\text { Insufficient pre-stimulation } \\
\text { by pre-EMM }\end{array}$ & Prolong pre-stimulation time $(4 \sim 10 \mathrm{~h})$ \\
\hline & Old mTeSR 1 & mTeSR 1 in EMM1/2 should be freshly prepared \\
\hline & Poor B27 batch & Screen B27 batches for their capacity to support efficient differentiation \\
\hline \multirow[t]{4}{*}{$\begin{array}{l}\text { Low proportion of } \mathrm{AFP}^{+} \mathrm{SOX}^{+} \\
\text {cells by day } 15\end{array}$} & $\begin{array}{l}\text { Suboptimal performance of } \\
\text { previous steps }\end{array}$ & $\begin{array}{l}\text { Check and optimize the efficiency of differentiation during day } 0 \sim 4 \text { as } \\
\text { described above }\end{array}$ \\
\hline & Variability between lines & $\begin{array}{l}\text { Optimization may be required for specific lines. Advanced DMEMF12 (1\% } \\
\text { B27) can replace RPMI }\left(\begin{array}{lll}2 \% & \text { B27 }) \text { for selected lines }\end{array}\right.\end{array}$ \\
\hline & $\begin{array}{l}\text { Reduced activity of } \\
\text { cytokines }\end{array}$ & Use cytokines that have undergone $<3$ freeze-thaw cycles \\
\hline & Poor B27 batch & Change the B27 batch as described above \\
\hline \multirow[t]{2}{*}{$\begin{array}{l}\text { Poor efficiency of hepatobiliary } \\
\text { differentiation }\end{array}$} & $\begin{array}{l}\text { Suboptimal performance of } \\
\text { previous steps }\end{array}$ & Check and optimize the efficiency of previous differentiation steps \\
\hline & Variability between lines & $\begin{array}{l}\text { Redefine the optimal concentration of cholesterol }{ }^{+}-\mathrm{MIX}(5 \sim 10 \%) \text { in } \\
\text { HBMM. }\end{array}$ \\
\hline Poor functional performance & Variability between lines & $\begin{array}{l}\text { Reduce the concentration of cholesterol }{ }^{+}-\mathrm{MIX} \text { as described above. Besides, } \\
\text { Hepatozyme-SFM (Gibco) may replace HCM in HBMM for selected lines }\end{array}$ \\
\hline \multirow[t]{3}{*}{ Delayed differentiation } & $\begin{array}{l}\text { Insufficient habituation of } \\
\text { hPSCs on rhLaminin }\end{array}$ & $\begin{array}{l}\text { Gradually reduce the concentration of Laminin } 521 \text { at an interval of } 2 \\
\text { passages until reaching the target concentration of } 3 \mu \mathrm{g} / \mathrm{ml} \text {. }\end{array}$ \\
\hline & Low ratio of rhLaminin 521 & $\begin{array}{l}\text { Ensure the ratio of Laminin } 521 / 111 \text { is not lower than } 1: 3 \text { since Laminin } \\
111 \text { is not ideal for cell expansion before day } 9 \text {. Alternatively, redefine } \\
\text { the ratio as } 1: 1 \text { for selected lines. }\end{array}$ \\
\hline & $\begin{array}{l}\text { Exhausted cytokines/other } \\
\text { nutrients }\end{array}$ & Ensure the medium refreshment for every $24 \mathrm{~h}$. \\
\hline \multirow[t]{4}{*}{ Unexpected cell death } & $\begin{array}{l}\text { Inappropriate composition of } \\
\text { culture medium }\end{array}$ & $\begin{array}{l}\text { Prepare new medium and check the concentration of cytokines. Besides, } \\
\text { test the reagents for lot-to-lot variability }\end{array}$ \\
\hline & $\begin{array}{l}\text { Incorrect parameter-setting of } \\
\text { cell incubator }\end{array}$ & Check and calibrate $\mathrm{CO} 2$ and humidity levels in the incubator \\
\hline & Contamination of the culture & Try the differentiation again by sterile operation \\
\hline & $\begin{array}{l}\text { Low concentration of } \\
\text { Laminin }\end{array}$ & $\begin{array}{l}\text { The working concentration of Laminin } 521 / 111 \text { should not be lower than } \\
3 \mu \mathrm{g} / \mathrm{ml}\end{array}$ \\
\hline
\end{tabular}

by specific mutations, and then differentiate them into HBOs for the examination of pathological phenotypes and discovery of therapeutic strategies (29).

Besides providing a better model for human liver development and diseases, the HBOs may be used for toxicity screening and drug development. Methods for in vitro culture of human hepatocytes (30), as wells as the PSC-based hepatocyte-like cells (31) have been developed to address this limitation. The HBO system presents significantly more complex liver structures when compared with 2D monolayer hepatocytes, thus, possesses a higher potential to precisely predict drug metabolism and toxicity. Compared to our previous 45-day differentiation system (16), the current protocol shortens the differentiation to 35 days, and more importantly, it enables $\mathrm{HBO}$ in vitro maintenance for more than 1.5 months without functional loss and meets the requirement of the applications with long-term intervention and analysis. 
Naturally, there are a few limitations for current system. One of the important considerations is the maturity of the generated HBOs, which exhibit a mixed functional phenotype between fetal and adult liver (referred to the expression profile of hepatobiliary markers (16), ALB and urea production, CYP3A4 activity and inducibility, and GGT activity). Therefore, before modeling adult hepatobiliary disorders, HBOs should be examined for the presence of mature markers and functionality. Recently, Mun et al. (32) reported that the R-spondin approach could be applied to expand the hPSC-derived hepatic lineage under $5 \%$ hypoxia condition. The expandable potential of our system may be investigated by setting hypoxic condition.

Our differentiation method worked well for all the human ES (H1 and H9) and iPS (UC-S0730C11 and WD1KSR-3) cell lines examined in this study. Owing to intrinsic variability in human iPS and ES cell lines (33-35), however, researchers may need to adjust the protocol depending on the cell lines they used. As shown in the Troubleshooting table (Table 1), some of the modifications may include the use of different concentrations of the cytokines, adjusting the timing of induction for each differentiation stage, as well as altering concentration or the type of cell culture substrate.

In summary, we herein present a detailed protocol for differentiation of hPSC into functional HBOs. This stepwise differentiation closely mimics human hepaobiliary specification, in which the HBOs can be functionally maintained in vitro up to day 85. We expect these HBOs can be used as an alternative cell source for studies of human hepatobiliary regeneration, disease mechanism, toxicology studies, or drug development.

\section{Acknowledgments}

This study was supported in part by National Natural Science Foundation of China (Grant No. 31871244), Natural Science Foundation of Guangdong Province of China (Grant No. 2020A1515011314), Natural Science Foundation of Shenzhen City (Grant No. JCYJ2019080710 1401682), and Medical Health Science and Technology Project of Longgang District (Grant No. LGKCYLWS2019 000361).

\section{Potential Conflict of Interest}

The authors have no conflicting financial interest.

\section{Author Contributions}

DW and FW contributed to the concept and design of the study; DW, QC, WC and YZ contributed to acquis- ition of data and its analysis; DW, XC, and QC contributed to drafting of the manuscript; all authors contributed to interpretation of the data.

\section{Supplementary Materials}

Supplementary data including one table and one figure can be found with this article online at https://doi.org/10. 15283/ijsc20152

\section{References}

1. Trounson A, DeWitt ND. Pluripotent stem cells progressing to the clinic. Nat Rev Mol Cell Biol 2016;17:194-200

2. Cai J, Zhao Y, Liu Y, Ye F, Song Z, Qin H, Meng S, Chen Y, Zhou R, Song X, Guo Y, Ding M, Deng H. Directed differentiation of human embryonic stem cells into functional hepatic cells. Hepatology 2007;45:1229-1239

3. Song Z, Cai J, Liu Y, Zhao D, Yong J, Duo S, Song X, Guo Y, Zhao Y, Qin H, Yin X, Wu C, Che J, Lu S, Ding $M$, Deng H. Efficient generation of hepatocyte-like cells from human induced pluripotent stem cells. Cell Res 2009; 19:1233-1242

4. Zhao D, Chen S, Duo S, Xiang C, Jia J, Guo M, Lai W, $\mathrm{Lu}$ S, Deng H. Promotion of the efficient metabolic maturation of human pluripotent stem cell-derived hepatocytes by correcting specification defects. Cell Res 2013;23:157161

5. Noto FK, Duncan SA. Generation of hepatocyte-like cells from human pluripotent stem cells. In: Sell S, editor. Stem Cells Handbook. New York: Humana Press; 2013. 139-147

6. Takebe T, Sekine K, Enomura $M$, Koike H, Kimura $M$, Ogaeri T, Zhang RR, Ueno Y, Zheng YW, Koike N, Aoyama S, Adachi Y, Taniguchi H. Vascularized and functional human liver from an iPSC-derived organ bud transplant. Nature 2013;499:481-484

7. Guye P, Ebrahimkhani MR, Kipniss N, Velazquez JJ, Schoenfeld E, Kiani S, Griffith LG, Weiss R. Genetically engineering self-organization of human pluripotent stem cells into a liver bud-like tissue using Gata6. Nat Commun 2016;7:10243

8. Duncan AW, Dorrell C, Grompe M. Stem cells and liver regeneration. Gastroenterology 2009;137:466-481

9. Huch M, Gehart H, van Boxtel R, Hamer K, Blokzijl F, Verstegen MM, Ellis E, van Wenum M, Fuchs SA, de Ligt J, van de Wetering M, Sasaki N, Boers SJ, Kemperman H, de Jonge J, Ijzermans JN, Nieuwenhuis EE, Hoekstra R, Strom S, Vries RR, van der Laan LJ, Cuppen E, Clevers $\mathrm{H}$. Long-term culture of genome-stable bipotent stem cells from adult human liver. Cell 2015;160:299-312

10. Raynaud P, Carpentier R, Antoniou A, Lemaigre FP. Biliary differentiation and bile duct morphogenesis in development and disease. Int J Biochem Cell Biol 2011;43: 245-256

11. Sherlock S, Dooley JS. Diseases of the liver and biliary 
system. 11th ed. Oxford: Blackwell Science; 2002. 597-623

12. Dianat N, Dubois-Pot-Schneider H, Steichen C, Desterke C, Leclerc P, Raveux A, Combettes L, Weber A, Corlu A, Dubart-Kupperschmitt A. Generation of functional cholangiocyte-like cells from human pluripotent stem cells and HepaRG cells. Hepatology 2014;60:700-714

13. Sampaziotis F, de Brito MC, Madrigal P, Bertero A, Saeb-Parsy K, Soares FAC, Schrumpf E, Melum E, Karlsen TH, Bradley JA, Gelson WT, Davies S, Baker A, Kaser A, Alexander GJ, Hannan NRF, Vallier L. Cholangiocytes derived from human induced pluripotent stem cells for disease modeling and drug validation. Nat Biotechnol 2015;33: 845-852

14. Ogawa M, Ogawa S, Bear CE, Ahmadi S, Chin S, Li B, Grompe M, Keller G, Kamath BM, Ghanekar A. Directed differentiation of cholangiocytes from human pluripotent stem cells. Nat Biotechnol 2015;33:853-861

15. Prior N, Inacio P, Huch M. Liver organoids: from basic research to therapeutic applications. Gut 2019;68:2228-2237

16. Wu F, Wu D, Ren Y, Huang Y, Feng B, Zhao N, Zhang $\mathrm{T}$, Chen X, Chen S, Xu A. Generation of hepatobiliary organoids from human induced pluripotent stem cells. J Hepatol 2019;70:1145-1158

17. Takayama $K$, Inamura $M$, Kawabata $K$, Sugawara $M$, Kikuchi K, Higuchi M, Nagamoto Y, Watanabe H, Tashiro K, Sakurai F, Hayakawa T, Furue MK, Mizuguchi H. Generation of metabolically functioning hepatocytes from human pluripotent stem cells by FOXA2 and HNF1 $\alpha$ transduction. J Hepatol 2012;57:628-636

18. Loh KM, Chen A, Koh PW, Deng TZ, Sinha R, Tsai JM, Barkal AA, Shen KY, Jain R, Morganti RM, Shyh-Chang N, Fernhoff NB, George BM, Wernig G, Salomon REA, Chen Z, Vogel H, Epstein JA, Kundaje A, Talbot WS, Beachy PA, Ang LT, Weissman IL. Mapping the pairwise choices leading from pluripotency to human bone, heart, and other mesoderm cell types. Cell 2016;166:451-467

19. Lu J, Zhong X, Liu H, Hao L, Huang CT, Sherafat MA, Jones J, Ayala M, Li L, Zhang SC. Generation of serotonin neurons from human pluripotent stem cells. Nat Biotechnol 2016;34:89-94

20. Carpentier A, Nimgaonkar I, Chu V, Xia Y, Hu Z, Liang TJ. Hepatic differentiation of human pluripotent stem cells in miniaturized format suitable for high-throughput screen. Stem Cell Res 2016;16:640-650

21. Touboul T, Chen S, To CC, Mora-Castilla S, Sabatini K, Tukey RH, Laurent LC. Stage-specific regulation of the WNT/ $\beta$-catenin pathway enhances differentiation of hESCs into hepatocytes. J Hepatol 2016;64:1315-1326

22. Tian L, Deshmukh A, Ye Z, Jang YY. Efficient and controlled generation of $2 \mathrm{D}$ and $3 \mathrm{D}$ bile duct tissue from human pluripotent stem cell-derived spheroids. Stem Cell Rev Rep 2016;12:500-508

23. Ober EA, Lemaigre FP. Development of the liver: insights into organ and tissue morphogenesis. J Hepatol 2018;68: 1049-1062
24. Trépo E, Romeo S, Zucman-Rossi J, Nahon P. PNPLA3 gene in liver diseases. J Hepatol 2016;65:399-412

25. Geisler F, Nagl F, Mazur PK, Lee M, Zimber-Strobl U, Strobl LJ, Radtke F, Schmid RM, Siveke JT. Liver-specific inactivation of Notch2, but not Notch1, compromises intrahepatic bile duct development in mice. Hepatology 2008;48: 607-616

26. Benam KH, Dauth S, Hassell B, Herland A, Jain A, Jang KJ, Karalis K, Kim HJ, MacQueen L, Mahmoodian R, Musah S, Torisawa YS, van der Meer AD, Villenave R, Yadid M, Parker KK, Ingber DE. Engineered in vitro disease models. Annu Rev Pathol 2015;10:195-262

27. Greek R, Menache A. Systematic reviews of animal models: methodology versus epistemology. Int J Med Sci 2013;10: 206-221

28. Yang L, Yang JL, Byrne S, Pan J, Church GM. CRISPR/Cas9-directed genome editing of cultured cells. Curr Protoc Mol Biol 2014;107:31.1.1-31.1.17

29. Guan Y, Xu D, Garfin PM, Ehmer U, Hurwitz M, Enns G, Michie S, Wu M, Zheng M, Nishimura T, Sage J, Peltz G. Human hepatic organoids for the analysis of human genetic diseases. JCI Insight 2017;2:e94954

30. Levy G, Bomze D, Heinz S, Ramachandran SD, Noerenberg A, Cohen M, Shibolet O, Sklan E, Braspenning J, Nahmias Y. Long-term culture and expansion of primary human hepatocytes. Nat Biotechnol 2015;33:1264-1271

31. Avior Y, Levy G, Zimerman M, Kitsberg D, Schwartz R, Sadeh R, Moussaieff A, Cohen M, Itskovitz-Eldor J, Nahmias Y. Microbial-derived lithocholic acid and vitamin K2 drive the metabolic maturation of pluripotent stem cells-derived and fetal hepatocytes. Hepatology 2015;62:265278

32. Mun SJ, Ryu JS, Lee MO, Son YS, Oh SJ, Cho HS, Son MY, Kim DS, Kim SJ, Yoo HJ, Lee HJ, Kim J, Jung CR, Chung KS, Son MJ. Generation of expandable human pluripotent stem cell-derived hepatocyte-like liver organoids. J Hepatol 2019;71:970-985

33. Osafune K, Caron L, Borowiak M, Martinez RJ, FitzGerald CS, Sato Y, Cowan CA, Chien KR, Melton DA. Marked differences in differentiation propensity among human embryonic stem cell lines. Nat Biotechnol 2008;26:313315

34. Närvä E, Autio R, Rahkonen N, Kong L, Harrison N, Kitsberg D, Borghese L, Itskovitz-Eldor J, Rasool O, Dvorak P, Hovatta O, Otonkoski T, Tuuri T, Cui W, Brüstle O, Baker D, Maltby E, Moore HD, Benvenisty N, Andrews PW, Yli-Harja O, Lahesmaa R. High-resolution DNA analysis of human embryonic stem cell lines reveals culture-induced copy number changes and loss of heterozygosity. Nat Biotechnol 2010;28:371-377

35. Chen XM, Kan QC, Wang F, Kong HJ, Zhang YY, Yu WZ, Sun YP. Chromosome dynamic changes in two cultured Chinese human embryonic stem cell lines: single nucleotide polymorphism, copy number variation and loss of heterozygosity. J Cell Biochem 2012;113:3520-3527 